\title{
Factors Associated with the Quality of Life of Patients with Cancer Undergoing Radiotherapy
}

\author{
Ki Ho Seol' ${ }^{1}$, Su Hyun Bong ${ }^{2}$, Dae Hun Kang ${ }^{3}$, and Jun Won Kim ${ }^{2 凶}$ \\ ${ }^{1}$ Department of Radiation Oncology, Catholic University of Daegu School of Medicine, Daegu, Republic of Korea \\ ${ }^{2}$ Department of Psychiatry, Catholic University of Daegu School of Medicine, Daegu, Republic of Korea \\ ${ }^{3}$ Department of Psychiatry, The Armed Forces Daejeon Hospital, Daejeon, Republic of Korea
}

\begin{abstract}
Objective Approximately half of patients with cancer have comorbidities, such as adjustment disorder, major depressive disorder, and delirium. Radiotherapy can cause psychological problems, e.g., the fear of treatment and its side effects, anxiety, depression, and social isolation. Health-related quality of life (QoL) must be determined to evaluate the effectiveness of cancer treatment. We analyzed the clinical, psychological, and sociodemographic factors influencing the QoL of patients with cancer who were undergoing radiotherapy.

Methods Twenty-six patients undergoing radiotherapy (10 male, 16 female) were included. Sociodemographic and clinical data were collected prior to radiotherapy. Psychosocial factors were assessed by self-reported questionnaires before, immediately after, and 3 months after radiotherapy. A multivariate regression analysis identified factors affecting QoL at each time point.

Results Patients' diagnoses were breast, cervical, prostate, endometrial, rectal, hypopharyngeal, laryngeal, liver, gallbladder, esophageal, ovarian, lung, and skin cancers. Before radiotherapy, better resilience was significantly associated with a higher QoL score $\left(\mathrm{R}^{2}=0.199\right.$, $\mathrm{p}=0.033)$. Immediately after radiotherapy, financial difficulty was significantly associated with a lower QoL score $\left(R^{2}=0.274, p=0.010\right)$. Three months after radiotherapy, the presence of chronic disease $\left(R^{2}=0.398, p=0.002\right)$ and the severity of nausea and vomiting were significantly associated with a lower QoL score $\left(\mathrm{R}^{2}=0.278, \mathrm{p}=0.014\right)$.

Conclusion Resilience, financial difficulty, the presence of chronic diseases, and the severity of nausea and vomiting significantly influenced the QoL of patients with cancer who were undergoing radiotherapy. Factors affecting QoL varied at each time point. Thus, patients with cancer should undergo regular mental health assessments, including assessments of QoL. Multidimensional (physical, psychological, and social) approaches and individualized time-based interventions are needed to improve the QoL of cancer patients undergoing radiotherapy.

Psychiatry Investig 2021;18(1):80-87
\end{abstract}

Key Words Cancer patient, Radiotherapy, Mental health, Quality of life.

\section{INTRODUCTION}

Cancer is a major health problem and one of the leading causes of death in Korea. According to the annual report of the Korea Central Cancer Registry, 214,701 patients were newly diagnosed with cancer, and 76,855 died due to cancer. ${ }^{1}$ According to the 2017 Statistics Korea information regarding the causes of death, the most common cause of death in Korea was cancer, accounting for $27.6 \%$ of all deaths. ${ }^{2}$ Cancer affects not

\footnotetext{
Received: July 26, 2020 Revised: September 20, 2020

Accepted: November 1, 2020

$\bowtie$ Correspondence: Jun Won Kim, MD, PhD

Department of Psychiatry, Catholic University of Daegu School of Medicine, 33 Duryugongwon-ro 17-gil, Nam-gu, Daegu 42472, Republic of Korea

Tel: +82-53-650-4332, Fax: +82-53-623-1694, E-mail: f_affection@naver.com

(a) This is an Open Access article distributed under the terms of the Creative Commons Attribution Non-Commercial License (https://creativecommons.org/licenses/bync/4.0) which permits unrestricted non-commercial use, distribution, and reproduction in any medium, provided the original work is properly cited.
}

only physical health but also mental health, and a cancer diagnosis causes severe stress in patients. The psychological response to a cancer diagnosis involves the fear of losing independence, the fear of losing one's role in society and economic power, and the fear of premature death, and the patients may experience emotions such as denial, anxiety, anger, or guilt.-5 Some cancer patients have severe symptoms of anxiety and depression as a result of the cancer diagnosis and treatment, ${ }^{6,7}$ and approximately half are known to experience mental disorders, such as adjustment disorder, depressive disorder, and delirium. ${ }^{8}$

Most cancer patients are treated with surgery, chemotherapy, and radiotherapy. Among these treatments, the treatment method, mechanism, and side effects of radiotherapy are relatively poorly understood compared to the other treatment modalities. ${ }^{9}$ Radiotherapy is a type of cancer treatment that uses beams of intense energy to kill cancer cells in the area specifi- 
cally targeted by the clinician. Radiation primarily damages the deoxyribonucleic acid (DNA) of cells by ionizing the atoms that compose the DNA chain. ${ }^{10}$ Ionization results in broken atomic and molecular bonds; the generation of double-strand breaks in DNA is considered the dominant factor that causes cell death. Both malignant and normal cells in the treatment field are subject to the ionizing effects of radiation. External beam radiation is a noninvasive and localized treatment, unlike surgery, which is an invasive process, and chemotherapy, which is a systemic treatment. Although radiotherapy is a type of therapy that may result in the maintenance of a relatively high quality of life (QoL) ${ }_{11}^{11}$ treatment with radiotherapy also causes stress in patients and is known to be associated with the development of psychiatric symptoms in patients with cancer. ${ }^{12}$ Radiotherapy causes various side effects according to the treatment method and site of irradiation. Most of the effects of radiotherapy on normal tissues are attributed to cytotoxicity. ${ }^{13}$ Acute effects during radiotherapy are common, rarely serious, and usually self-limiting. Acute effects tend to occur in organs that depend on rapid self-renewal, most commonly the skin or mucosal surfaces (oropharynx, esophagus, stomach, small intestine, rectum, and bladder). Some effects are mediated by radiation-induced inflammatory cytokines. ${ }^{14} \mathrm{Ex}$ amples include nausea or vomiting that may occur a few hours after irradiation of the abdomen, fatigue experienced by patients receiving a large volume of irradiation, particularly within the abdomen, and acute edema or erythema resulting from radiation-induced acute inflammation and associated vascular leakage. Due to these side effects, some patients may experience psychological problems, such as anxiety, depression, and social isolation caused by the fear of radiotherapy itself or its side effects. ${ }^{9,12,15}$ In addition, by being reminded of the cancer diagnosis at each treatment session, the patients' mental distress may be exacerbated. ${ }^{16}$

The level of interest in the long-term treatment of chronic diseases has increased because of the longer life expectancy of patients. The survival rate of patients with cancer has also increased compared to previous years. The cancer mortality rate in Korea has decreased by $2.7 \%$ annually since 2002 , and the 5 -year survival rate of patients with cancer between 2011 and 2015 was 70.7\%, which increased from 41.2\% between 1993 and $1995 .{ }^{1}$ According to the 2016 cancer prevalence statistics in Korea from the National Cancer Information Center, 3.4\% $(1,739,951)$ of Korean nationals $(51,112,980)$ were undergoing cancer treatment or had survived treatment, and among elderly people aged 65 years or older, $11.0 \%(747,898)$ were undergoing cancer treatment or had survived treatment. ${ }^{17}$ As the difference in the survival rates between patients with a chronic disease and the general population has decreased, QoL has been recognized as an important factor in determining the effects of treatment on patients in the clinical setting. ${ }^{18}$

Health-related QoL is a subjective and multidimensional concept defined as a 'patient's perception of the functional effect of the disease or disease treatment, ${ }^{19}$ and it is considered one of the important treatment outcomes in oncology. ${ }^{20} \mathrm{In}$ several previous studies of patients with cancer, QoL was related to survival ${ }^{21}$ and affected the decisions made by the medical staff regarding the method of treatment and patients' evaluation of and compliance with treatment. ${ }^{20}$ In previous studies, the QoL of patients with cancer was associated with race, cancer type, combination therapy, fatigue, performance status, satisfaction with the explanation provided by the medical staff, and a depressive mood. ${ }^{22-24}$ However, the overall health status, psychological state, and social environment change over time in the course of cancer treatment, including treatment with radiotherapy, and the factors affecting the QoL may vary, depending on the time point in the course of treatment. Identifying the differences in factors affecting the QoL of patients with cancer before and after radiotherapy may help researchers understand what factors are important for patients over time, which may facilitate an improvement in the QoL of this population. Thus, in this study, we investigated the sociodemographic and clinical data of cancer patients who were treated with radiotherapy and evaluated their QoL and psychosocial factors before and after radiotherapy. We aimed to analyze the factors that influence the QoL of patients with cancer undergoing radiotherapy at each time point before and after radiotherapy.

\section{METHODS}

\section{Subjects}

This study was conducted at the outpatient clinic of the Radiation Oncology Department, Daegu Catholic University Hospital, in 2018. Inclusion criteria were as follows: treatment with a curative intent (including oligometastasis); an Eastern Cooperative Oncology Group performance status of 0-1; 18 years of age or older; patients who did not have a significant complaint before radiotherapy, except for pain associated with primary tumor; and patients treated with three-dimensional conformal or intensity-modulated external beam radiotherapy. Twenty-six cancer patients (10 male and 16 female) voluntarily agreed to participate after receiving an explanation of the purpose and methodology of the study, the expected benefits and risks, and confidentiality. The sociodemographic and clinical data of the participants were acquired before the initiation of radiotherapy. Sociodemographic data and the medical history were recorded directly by the participants, and clinical information about the cancer was obtained by a radiation oncologist from the medical records. Self-reported questionnaires were administered before, immediately after, and 3 months 
after the completion of radiotherapy to evaluate the psychosocial factors, including the QoL of the participants. This study was approved by the Institutional Review Board of Daegu Catholic University Hospital (Study No. CR-17-136).

\section{Study tools}

The European Organization for Research and Treatment of Cancer (EORTC) Quality of Life Questionnaire-Core 30 (EORTC-QLQ-C30)

This questionnaire was designed to assess health-related QoL in patients with cancer, and it consists of 28 items rated on a scale from 1 to 4 points and 2 items rated on a scale from 1 to 7 points. ${ }^{25}$ It consists of five functional subscales (physical, role, cognitive, emotional, and social), three symptom subscales (fatigue, pain, and nausea/vomiting), six single items (dyspnea, appetite loss, insomnia, constipation, diarrhea, and financial difficulty), a global health scale, and a QoL scale. Each subscale and single item score is expressed in terms of the proportion of the total score. A higher functional scale score indicates better function, and higher symptom scale and single item scores indicate more severe symptoms. Higher global health and QoL scale scores indicate better global health and QoL, respectively. In this study, we used the Korean version, which was translated from the EORTC (version 3.0, 1995), after approval from the EORTC website (URL: https://qol.eortc.org/ questionnaires/).

\section{Beck Depression Inventory-II (BDI-II)}

This questionnaire was designed by Beck to measure the severity of clinical depression symptoms. ${ }^{26}$ It consists of 21 items scored on scales from 0 to 3 ; these items include cognitive, emotional, motivational, and somatic symptoms. The total score ranges from 0 to 63 , and a higher total score means more severe depressive symptoms. In this study, we used the scale validated by Sung et al. ${ }^{27}$

\section{Beck Anxiety Inventory (BAI)}

This questionnaire was developed by Beck to measure the severity of anxiety and to distinguish between anxiety and depression. ${ }^{28}$ It consists of 21 items scored on a scale from 0 to 3 ; these items include cognitive, emotional, and somatic symptoms of anxiety. The total score ranges from 0 to 63 , and a higher total score means more severe anxiety symptoms. In this study, we used the scale translated by Kwon. ${ }^{29}$

\section{Perceived Stress Scale (PSS)}

This questionnaire was developed by Cohen et al. ${ }^{30}$ to evaluate the degree of stress experienced by an individual. It consists of 5 positive and 5 negative stress perception questions scored from 0 to 4; these questions ask about feelings and thoughts during the last month. The total score is obtained by summing the scores of the 5 negative items and the inverse of the scores of the 5 positive items. The total score ranges from 0 to 40 , and a higher score indicates a more severe degree of subjectively perceived stress. In this study, we used the scale translated and validated by Park and Seo. ${ }^{31}$

\section{Rosenberg Self Esteem Scale (RSES)}

This questionnaire was developed by Rosenberg to measure self-esteem and self-acceptance. It consists of 5 positive and 5 negative self-esteem items scored from 1 to 4 . The total score is obtained by summing the scores of the 5 positive items and the inverse of the scores of the 5 negative items, and the total ranges from 10 to 40 , with a higher score indicating better selfesteem. In this study, we used the scale translated by Jon. ${ }^{32}$

\section{Conner-Davidson Resilience Scale (CD-RISC)}

This questionnaire was developed by Conner and Davidson to measure resilience, which is defined as the ability to successfully cope with stress. ${ }^{33}$ It consists of 25 items scored from 0 to 4 points, and the total score ranges from 0 to 100 points. A higher total score indicates better resilience. In this study, we used the scale validated by Jung et al. ${ }^{34}$

\section{Lubben Social Network Scale (LSNS)}

This questionnaire was developed by Lubben ${ }^{35}$ to evaluate the level of social support. The short version used in our study consists of 6 items scored from 0 to 5 points; these items inquire about the family network and the friends network. The total score ranges from 0 to 30 , and a higher total score indicates a better social network. In this study, we used the scale translated by Lee et al. ${ }^{36}$

\section{Statistical analysis}

All data were analyzed using SPSS for Windows version 18.0 (SPSS Inc., Chicago, IL, USA), and statistical significance was defined as $\mathrm{p}<0.05$. The demographics, clinical characteristics and self-reported results were analyzed with descriptive statistics. Multiple regression analysis was performed to identify factors that affected the participants' QoL at each time point. One of the EORTC-QLQ-C30 subscales, the QoL subscale, was used as a dependent variable. Sociodemographic and clinical data and all the other self-reported results, except the EORTCQLQ-C30 global health subscale and QoL subscale scores, were used as independent variables. 


\section{RESULTS}

\section{Sociodemographic characteristics}

The mean age of the participants was $56.15( \pm 10.40)$ years. Thirteen (50\%) had graduated from high school, and 13 (50\%) had a monthly income of less than 2 million won. At the time of radiotherapy initiation, $9(34.6 \%)$ patients consumed alcohol, and $6(23.1 \%)$ patients were smokers (Table 1 ).

\section{Clinical characteristics}

The diagnoses received by the subjects were as follows: breast cancer in 7 (26.9\%), cervical cancer in $4(15.4 \%)$, prostate cancer in $3(11.5 \%)$, endometrial cancer in $2(7.7 \%)$, rectal cancer in 2 (7.7\%), hypopharyngeal cancer in $1(3.8 \%)$, laryngeal cancer in $1(3.8 \%)$, liver cancer in $1(3.8 \%)$, ovarian cancer in 1 (3.8\%), gallbladder cancer in $1(3.8 \%)$, esophageal cancer in 1 (3.8\%), lung cancer in $1(3.8 \%)$, and skin cancer in $1(3.8 \%)$ (Table 2). The most frequent stage of cancer identified in the participants was stage III (10, 38.5\%); 25 participants (96.2\%) had been diagnosed for the first time at the time of enrolment, and 24 (92.3\%) participants did not have metastasis. Eleven (42.3\%) participants underwent chemotherapy, 10 (38.5\%) participants underwent surgical treatment, and 5 (19.2\%) participants underwent both chemotherapy and surgical treatment.

Table 1. Sociodemographic characteristics of participants

\begin{tabular}{|c|c|}
\hline Characteristics & Mean \pm SD or $\mathrm{N}(\%)$ \\
\hline Age & $56.15 \pm 10.40$ \\
\hline \multicolumn{2}{|l|}{ Sex } \\
\hline Male & $10(38.5)$ \\
\hline Female & $16(61.5)$ \\
\hline \multicolumn{2}{|l|}{ Education } \\
\hline Elementary school education or lower & $4(15.4)$ \\
\hline Middle school education & $3(11.5)$ \\
\hline High school education & $13(50.0)$ \\
\hline College degree or higher & $6(23.1)$ \\
\hline \multicolumn{2}{|l|}{ Monthly income } \\
\hline$<2,000,000$ won & $13(50.0)$ \\
\hline $2,000,000-3,999,999$ won & $5(19.2)$ \\
\hline $4,000,000-5,999,999$ won & $4(15.4)$ \\
\hline$\geq 6,000,000$ won & $2(7.7)$ \\
\hline \multicolumn{2}{|l|}{ Alcohol use } \\
\hline Yes & $9(34.6)$ \\
\hline No & $17(63.4)$ \\
\hline \multicolumn{2}{|l|}{ Tobacco use } \\
\hline Yes & $6(23.1)$ \\
\hline No & $20(76.9)$ \\
\hline
\end{tabular}

SD: standard deviation, N: number of patients
Nine (34.6\%) participants experienced pain, and 20 (76.9\%) participants experienced side effects from radiotherapy. Two (7.7\%) participants had a history of mental disorders, and 11 (42.3\%) participants had other chronic illnesses (Table 3).

\section{Factors associated with QoL before and after radiotherapy}

The mean QoL scores of participants before, immediately after, and 3 months after the completion of radiotherapy as evaluated using the EORTC-QLQ-C-30 QoL scale were 67.31 $( \pm 20.26), 66.67( \pm 17.63)$, and $69.44( \pm 21.79)$, respectively (Figure 1). Before initiating radiotherapy, better resilience, as evaluated by the CD-RISC, was significantly associated with a higher QoL score ( $\beta=0.447, \mathrm{p}=0.033)$, and it accounted for $19.9 \%$ of the QoL. Immediately after radiotherapy, financial difficulty, as evaluated by the EORTC-QLQ-C30 single item, was significantly associated with a lower QoL score $(\beta=-0.524, \mathrm{p}=$ 0.010 ), and it accounted for $27.4 \%$ of the QoL. Three months after the end of radiotherapy, the presence of other chronic diseases $(\beta=-0.549, p=0.002)$ and the severity of nausea and vomiting symptoms evaluated using the EROTC-QLQ-C30 symptom scale $(\beta=-0.419, \mathrm{p}=0.014)$ were significantly associated with a lower QoL score, and these factors accounted for $55.9 \%$ of the QoL (Table 4). The relationships between other factors and QoL were not statistically significant.

\section{DISCUSSION}

As the survival rate of cancer patients has increased, the importance of QoL when setting treatment goals has been increasingly emphasized. The purpose of this study was to identify the factors that influence the QoL of patients with cancer

Table 2. Tumor locations in participants

\begin{tabular}{ll}
\hline \multicolumn{1}{c}{ Tumor location } & $\mathrm{N}(\%)$ \\
\hline Breast & $7(26.9)$ \\
Cervix & $4(15.4)$ \\
Prostate & $3(11.5)$ \\
Endometrium & $2(7.7)$ \\
Rectum & $2(7.7)$ \\
Hypopharynx & $1(3.8)$ \\
Larynx & $1(3.8)$ \\
Liver & $1(3.8)$ \\
Gall bladder & $1(3.8)$ \\
Esophagus & $1(3.8)$ \\
Ovary & $1(3.8)$ \\
Lung & $1(3.8)$ \\
Skin & $1(3.8)$ \\
\hline
\end{tabular}

$\mathrm{N}$ : number of patients 
Table 3. Clinical characteristics of participants

\begin{tabular}{|c|c|}
\hline Characteristics & $\mathrm{N}(\%)$ \\
\hline \multicolumn{2}{|l|}{ Tumor stage } \\
\hline 0 & $2(7.7)$ \\
\hline I & $4(15.4)$ \\
\hline II & $7(26.9)$ \\
\hline III & $10(38.5)$ \\
\hline IV & $3(11.5)$ \\
\hline \multicolumn{2}{|l|}{ Relapse } \\
\hline Yes & $1(3.8)$ \\
\hline No & $25(96.2)$ \\
\hline \multicolumn{2}{|l|}{ Metastases } \\
\hline Yes & $2(7.7)$ \\
\hline No & $24(92.3)$ \\
\hline \multicolumn{2}{|l|}{ Chemotherapy } \\
\hline Yes & $16(61.5)$ \\
\hline No & $10(38.5)$ \\
\hline \multicolumn{2}{|l|}{ Surgery } \\
\hline Yes & $15(57.7)$ \\
\hline No & $11(42.3)$ \\
\hline \multicolumn{2}{|l|}{ Pain } \\
\hline Yes & $9(34.6)$ \\
\hline No & $17(63.4)$ \\
\hline \multicolumn{2}{|c|}{ Adverse effects of radiotherapy* } \\
\hline No & $6(23.1)$ \\
\hline G1-2 & $19(73.1)$ \\
\hline G3-4 & $1(3.8)$ \\
\hline \multicolumn{2}{|l|}{ History of mental disorders } \\
\hline Yes & $2(7.7)$ \\
\hline No & $24(92.3)$ \\
\hline \multicolumn{2}{|l|}{ History of chronic diseases } \\
\hline Yes & $11(42.3)$ \\
\hline No & $15(57.7)$ \\
\hline
\end{tabular}

*based on the common terminology of criteria for adverse events 4.0. N: number of patients

who visited the outpatient clinic of the Radiation Oncology Department of Daegu Catholic University Hospital before and after radiotherapy. The main findings of this study were as follows. First, before the initiation of radiotherapy, better resilience was associated with a higher QoL score. Second, immediately after the end of radiotherapy, financial difficulty was associated with a lower QoL score. Third, 3 months after the end of radiotherapy, the presence of chronic disease and the severity of nausea and vomiting symptoms were associated with a lower QoL score.

The results of this study showed that before the initiation of radiotherapy, better resilience was associated with better QoL.

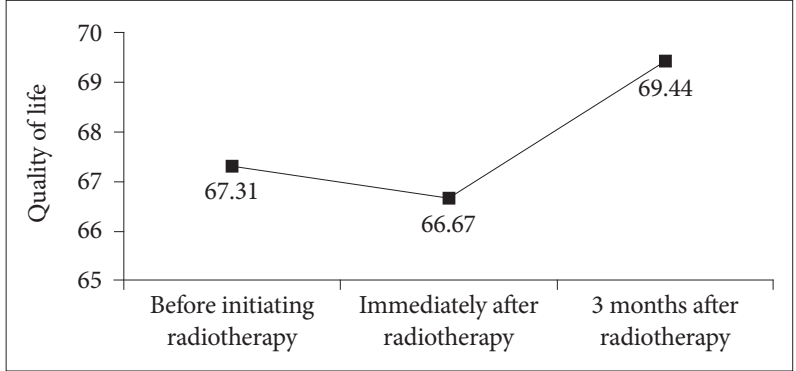

Figure 1. Quality of life of participants.

Resilience refers to the ability of an individual to maintain or recover a healthy state by coping effectively when encountering adversity. ${ }^{37}$ The emotional distress, such as depression and anxiety, experienced by patients with cancer because of the diagnosis and treatment of cancer decreases their QoL and interferes with adherence to treatment. ${ }^{20}$ Previous studies of patients with cancer have identified a contribution of resilience to decreasing emotional distress, ${ }^{38}$ and it may ameliorate the decrease in QoL due to emotional distress. ${ }^{39}$ In addition, a high degree of resilience might help improve QoL by alleviating the emotional distress experienced by patients who have been newly diagnosed with cancer and facilitating the use of better coping strategies. ${ }^{40}$ All of the participants in this study, except one, were diagnosed with cancer for the first time and had not experienced a relapse. The participants with good resilience might not have experienced a decrease in their QoL because they were better able to cope with the life crisis of a cancer diagnosis, and their better resilience ameliorated the emotional distress resulting from the cancer diagnosis. Thus, a potentially helpful approach would be to screen patients for low resilience in addition to significant emotional distress, such as depression and anxiety, immediately after a cancer diagnosis is made. Along with appropriate interventions, this screening procedure may contribute to improving the QoL of patients with cancer by increasing their resilience and alleviating the negative emotions caused by the cancer diagnosis. However, the time that elapsed from the first cancer diagnosis to enrolment in the study ranged from 1 month to 8 months for each participant. After receiving a diagnosis, patients have time to accept cancer as part of their lives and develop resistance to other stressors related to cancer. ${ }^{39}$ Thus, the effect of the cancer diagnosis on the QoL of the participant might vary depending on the time that elapsed since the cancer diagnosis, but we did not consider this factor as a variable in the present study.

Immediately after radiotherapy, financial difficulty due to poor health and cancer treatment costs was associated with a worse QoL. This result was consistent with the findings of previous studies showing an association between financial difficulty and poor QoL of patients with cancer. ${ }^{41-43}$ Patients with cancer may experience substantial financial burdens due to 
Table 4. Associations of QoL with variables determined using the multivariate regression analysis

\begin{tabular}{|c|c|c|c|c|c|}
\hline & Beta & $\mathrm{t}$ & $\mathrm{R}^{2}$ & Adjusted $\mathrm{R}^{2}$ & $\mathrm{p}$ value \\
\hline \multicolumn{6}{|l|}{ Before initiating radiotherapy } \\
\hline Resilience & 0.447 & 2.288 & 0.199 & 0.161 & 0.033 \\
\hline \multicolumn{6}{|l|}{ Immediately after radiotherapy } \\
\hline Financial difficulty & -0.524 & -2.816 & 0.274 & 0.239 & 0.010 \\
\hline \multicolumn{6}{|l|}{3 months after radiotherapy } \\
\hline Presence of chronic diseases & -0.549 & -3.547 & 0.559 & 0.513 & 0.002 \\
\hline Nausea and vomiting & -0.419 & -2.705 & & 0.014 & \\
\hline
\end{tabular}

the cost of treatments such as radiotherapy, chemotherapy, and surgery; ${ }^{44}$ a decrease in productivity at the workplace or unemployment; ${ }^{45}$ and a decrease in the family income because of the costs of caring for the patients. ${ }^{46}$ The financial burden on patients with cancer may reduce their QoL by increasing their risk of using their savings, reducing the money available for groceries, delaying vacations, and necessitating longer work hours. ${ }^{47}$ The financial burden on patients with cancer is known to increase the mortality rate because it negatively affects their well-being and health-related QoL, and an attempt to reduce the financial burden interferes with treatment compliance and the quality of care..$^{48}$ In a previous study conducted in Korea, the highest incidence of overspending, which was defined as an annual household medical expenditure of more than 10\% of the total annual household income, was observed during the first year after a cancer diagnosis. ${ }^{49}$ All of the participants in this study received combination therapy including chemotherapy, surgical treatment, or both. At the time point immediately after the completion of radiotherapy, the duration of cancer had been relatively short, from 3 months to 10 months. Based on these results, we postulate that patients with cancer experience financial burdens starting at the beginning of treatment. Immediately after completing radiotherapy, participants who started cancer therapy for the first time or who started radiotherapy as a new therapy seemed to experience a relatively large impact of the financial burden on their QoL. Therefore, when administering radiotherapy to patients with cancer, clinicians should consider that the household income and financial burden may substantially affect the patients' QoL.

Three months after radiotherapy, the presence of chronic disease and the severity of nausea and vomiting symptoms were associated with worse quality of life. Three of the participants in this study had diabetes, 3 had hypertension, 3 had both diabetes and hypertension, 1 had arthritis, and 1 had prostate disease. Diabetes has been shown to negatively affect QoL, depending on the type and use of medication and comorbidities, ${ }^{50}$ and hypertension is also associated with a worse QoL. ${ }^{50,51} \mathrm{~Pa}$ tients with cancer often experience nausea and vomiting because of direct or indirect complications of cancer and the tox- icity of the chemotherapy or radiotherapy. ${ }^{52}$ These symptoms may adversely affect QoL by deteriorating the nutritional status of the patient and interfering with their pleasure in eating. ${ }^{52,53}$ In particular, patients with head and neck cancer and gastrointestinal cancer are more likely to experience nausea or develop malnutrition after radiotherapy than patients with other types of cancer. ${ }^{54,55}$ Patients with head and neck cancer have a worse QoL before and after radiotherapy than patients with other types of cancer. ${ }^{54}$ In the same study mentioned above, increased nutritional intake after radiotherapy was associated with an improved QoL of patients with head and neck cancer. ${ }^{54}$ Three months after the completion of radiotherapy, the impact of the cancer diagnosis on QoL may be reduced, and QoL is affected by coexisting chronic diseases and nausea and vomiting that occur as a result of the cancer or its treatment. Therefore, after the completion of radiotherapy, the overall mental health, including QoL, of patients with chronic diseases and severe side effects, such as nausea and vomiting, caused by the cancer treatment should be closely monitored. In addition, clinicians should attempt to effectively control side effects, such as nausea and vomiting.

The limitations of this study were as follows. First, the results of this study are difficult to generalize because all of the participants were recruited from one hospital outpatient clinic, and the number of participants was relatively small. Second, the participants had several types of cancer, but the types of cancer were not considered in the analysis. Therefore, the differences in the symptoms and side effects that might occur depending on the cancer type and the irradiation site were not reflected in the results. Third, treatment-related factors such as the total dose and fractionation of radiotherapy, concurrent chemotherapy, and surgery were not thoroughly considered in the analysis. We expected these factors to affect QoL. However, these factors were removed during stepwise selection. Although concurrent chemotherapy may exert a significant effect on QoL, the main purpose of concurrent chemotherapy administered to the patients enrolled in this study was to increase the effectiveness of radiotherapy as a radiosensitizer. Since radiotherapy was performed after a sufficient re- 
covery time after surgery, the effect of surgery was likely to be minimal. This discrepancy might also be due to the very small number of subjects in this study. Therefore, further studies on whether chemotherapy and surgery and age affect QoL during radiotherapy are needed. Fourth, follow-up was terminated 3 months after the completion of radiotherapy. Therefore, the results do not reflect the effects of late-onset side effects of radiotherapy, which may have appeared after the end of this follow-up period. Fifth, in the analysis, the overall QoL determined using the EORTC-QLQ-C30 was used as a dependent variable. Thus, the results do not reflect the multidimensional aspects of health-related QoL. Sixth, the cancer disease process occurs over a long period, but the period of study participation was as short as 4-7 months at the initial stage of diagnosis. However, this study was meaningful because we tried to analyze the factors associated with the QoL of patients with cancer both before and after radiotherapy. In the future, studies of the long-term QoL and associated factors over the entire cancer disease process are needed.

In conclusion, the factors associated with the QoL of patients with cancer who were undergoing radiotherapy varied based on whether QoL was assessed before or after radiotherapy. Resilience influenced QoL before the initiation of radiotherapy, financial difficulty influenced QoL immediately after radiotherapy, and chronic disease and nausea and vomiting affected QoL 3 months after radiotherapy. Thus, regular assessments of mental health, including QoL, should be considered in cancer patients undergoing radiotherapy. Multidimensional approaches that consider physical, psychological, and social factors and individualized interventions designed for each time point are needed to improve the QoL of patients with cancer undergoing radiotherapy.

\section{Acknowledgments}

This study was supported by a grant from the Research Institute of Medical Science, Catholic University of Daegu (2019). The abstract of this paper was presented at the 'Consultation-Liaison Psychiatry 2019', which was organized by Academy of Consultation-Liaison Psychiatry (ACLP), as a poster presentation with interim findings from November 13-16, 2019.

\section{Conflicts of Interest}

The authors have no potential conflicts of interest to disclose.

\section{Author Contributions}

Conceptualization: Ki Ho Seol, Jun Won Kim. Data curation: Ki Ho Seol, Su Hyun Bong, Dae Hun Kang. Formal analysis: Dae Hun Kang, Jun Won Kim. Funding acquisition: Jun Won Kim. Investigation: Ki Ho Seol. Methodology: Ki Ho Seol, Jun Won Kim. Project administration: Jun Won Kim. Resources: Jun Won Kim. Software: Ki Ho Seol. Supervision: Jun Won Kim. Validation: Ki Ho Seol, Jun Won Kim. Visualization: Dae Hun Kang. Writing_original draft: Ki Ho Seol. Writing_review \& editing: Dae Hun Kang, Su Hyun Bong, Jun Won Kim.

\section{ORCID iDs}

Ki Ho Seol

Su Hyun Bong

Dae Hun Kang

Jun Won Kim

https://orcid.org/0000-0001-6206-6425

https://orcid.org/0000-0002-9492-9501

https://orcid.org/0000-0002-5115-4152

https://orcid.org/0000-0001-6793-3006

\section{REFERENCES}

1. Jung KW, Won YJ, Kong HJ, Lee ES. Cancer statistics in Korea: incidence, mortality, survival, and prevalence in 2015. Cancer Res Treat 2018;50:303-316.

2. Statics Korea. 2017 Cause of death statics. Available at: http://www.kostat.go.kr/portal/korea/kor_nw/1/6/2/index.board. Accessed Jul 31, 2019.

3. Antoni MH. Psychosocial intervention effects on adaptation, disease course and biobehavioral processes in cancer. Brain Behav Immun 2013;30: S88-S98.

4. Stanton AL. Psychosocial concerns and interventions for cancer survivors. J Clin Oncol 2006;24:5132-5137.

5. Cassileth BR, Lusk EJ, Strouse TB, Miller DS, Brown LL, Cross PA. A psychological analysis of cancer patients and their next-of-kin. Cancer 1985;55:72-76.

6. Stark D, Kiely M, Smith A, Velikova G, House A, Selby P. Anxiety disorders in cancer patients: their nature, associations, and relation to quality of life. J Clin Oncol 2002;20:3137-3148.

7. Massie MJ. Prevalence of depression in patients with cancer. J Natl Cancer Inst Monogr 2004;32:57-71.

8. van't Spijker A, Trijsburg RW, Duivenvoorden HJ. Psychological sequelae of cancer diagnosis: a meta-analytical review of 58 studies after 1980. Psychosom Med 1997;59:280-293.

9. Nasreldin M, Mostafa A, Raafat O, Azim SA, ElBatrawy M, Arafa M, et al. Psychotherapeutic intervention during radiotherapy: effects on emotional and physical symptoms. Middle East Curr Psychiatry 2012; 19:200-205.

10. Steel GG, McMillan TJ, Peacock JH. The 5Rs of radiobiology. Int J Radiat Biol 1989;56:1045-1048.

11. Shimotsu S, Karasawa K, Kawase E, Ito K, Saito AI, Izawa H, et al. An investigation of anxiety about radiotherapy deploying the Radiotherapy Categorical Anxiety Scale. Int J Clin Oncol 2010;15:457-461.

12. Peck A, Boland J. Emotional reactions to radiation treatment. Cancer 1977;40:180-184.

13. Prise KM, Schettino G, Folkard M, Held KD. New insights on cell death from radiation exposure. Lancet Oncol 2005;6:520-528.

14. Formenti SC, Demaria S. Systemic effects of local radiotherapy. Lancet Oncol 2009;10:718-726.

15. Sehlen S, Hollenhorst H, Schymura B, Herschbach P, Aydemir U, Firsching M, et al. Psychosocial stress in cancer patients during and after radiotherapy. Strahlenther Onkol 2003;179:175-180.

16. Holland JC, Rowland J, Lebovits A, Rusalem R. Reactions to cancer treatment: assessment of emotional response to adjuvant radiotherapy as a guide to planned intervention. Psychiatr Clin North Am 1979;2: 347-358.

17. National Cancer Information Center Korea. Cancer statics report. Available at: http://www.cancer.go.kr/lay1/S1T654C655/contents.do. Accessed Aug 1, 2019.

18. Katz S. The science of quality of life. J Chronic Dis 1987;40:459-463.

19. Lee SY, Choi SJ, Na YH. A review of the health-related quality of life. J Neurogastroenterol Motil 2001;7:6-17.

20. Frick E, Tyroller M, Panzer M. Anxiety, depression and quality of life of cancer patients undergoing radiation therapy: a cross-sectional study in a community hospital outpatient centre. Eur J Cancer Care 2007;16:130-136.

21. Montazeri A. Quality of life data as prognostic indicators of survival in cancer patients: an overview of the literature from 1982 to 2008. Health Qual Life Outcomes 2009;7:102. 
22. Husson O, Mols F, van de Poll-Franse LV. The relation between information provision and health-related quality of life, anxiety and depression among cancer survivors: a systematic review. Ann Oncol 2010; 22:761-772.

23. de Graeff A, de Leeuw JRJ, Ros WJ, Hordijk GJ, Blijham GH, Winnubst JA. Pretreatment factors predicting quality of life after treatment for head and neck cancer. Head Neck 2000;22:398-407.

24. Meeske KA, Patel SK, Palmer SN, Nelson MB, Parow AM. Factors associated with health-related quality of life in pediatric cancer survivors. Pediatr Blood Cancer 2007;49:298-305.

25. Aaronson NK, Ahmedzai S, Bergman B, Bullinger M, Cull A, Duez NJ, et al. The European Organization for Research and Treatment of Cancer QLQ-C30: a quality-of-life instrument for use in international clinical trials in oncology. J Natl Cancer Inst 1993;85:365-376.

26. Beck AT, Ward CH, Mendelson M, Mock J, Erbaugh J. An inventory for measuring depression. Arch Gen Psychiatry 1961;4:561-571.

27. Sung H, Kim J, Park Y, Bai D, Lee S, Ahn H. A study on the reliability and the validity of Korean version of the Beck Depression Inventory-II (BDI-II). J Korean Soc Biol Ther Psychiatry 2008;14:201-212.

28. Beck AT, Epstein N, Brown G, Steer RA. An inventory for measuring clinical anxiety: psychometric properties. J Consult Clin Psychol 1988; 56:893-897.

29. Kwon S. Assessment of psychopathology in anxiety disorder. Korean J Psychopathol 1997;6:37-51.

30. Cohen S, Kamarck T, Mermelstein R. A global measure of perceived stress. J Health Soc Behav 1983;24:385-396.

31. Park JO, Seo YS. Validation of the perceived stress scale (PSS) on samples of Korean university students. Korean J Psychol 2010;29:611-629.

32. Jon BJ. Self-esteem: a test of its measurability. Yonsei Collection of writings 1974;11:107-130.

33. Connor KM, Davidson JR. Development of a new resilience scale: the Connor-Davidson resilience scale (CD-RISC). Depress Anxiety 2003; 18:76-82.

34. Jung YE, Min JA, Shin AY, Han SY, Lee KU, Kim TS, et al. The Korean version of the Connor-Davidson Resilience Scale: an extended validation. Stress Health 2012;28:319-26.

35. Lubben JE. Assessing social networks among elderly populations. Fam Commun Health 1988;11:42-52.

36. Lee KW, Kim SY, Chung W, Hwang GS, Hwang YW, Hwang IH. The validity and reliability of Korean version of lubben social network scale. Korean J Fam Med 2009;30:352-358.

37. Jung YE, Chae JH. A review of resilience assessment tools. J Korean Neuropsychiatr Assoc 2010;49:50-57.

38. Min JA, Yoon S, Lee CU, Chae JH, Lee C, Song KY, et al. Psychological resilience contributes to low emotional distress in cancer patients. Support Care Cancer 2013;21:2469-2476.

39. Ye ZJ, Qiu HZ, Li PF, Liang MZ, Zhu YF, Zeng Z, et al. Predicting changes in quality of life and emotional distress in Chinese patients with lung, gastric, and colon-rectal cancer diagnoses: the role of psychological resilience. Psychooncology 2017;26:829-835.
40. Molina Y, Yi JC, Martinez-Gutierrez J, Reding KW, Yi-Frazier JP, Rosenberg AR. Resilience among patients across the cancer continuum: diverse perspectives. Clin J Oncol Nurs 2014;18:93-101.

41. Zafar SY, McNeil RB, Thomas CM, Lathan CS, Ayanian JZ, Provenzale D. Population-based assessment of cancer survivors' financial burden and quality of life: a prospective cohort study. J Oncol Pract 2015;11: 145-150.

42. Fenn KM, Evans SB, McCorkle R, DiGiovanna MP, Pusztai L, Sanft T, et al. Impact of financial burden of cancer on survivors' quality of life. J Oncol Pract 2014;10:332-338.

43. Gupta D, Lis CG, Grutsch JF. Perceived cancer-related financial difficulty: implications for patient satisfaction with quality of life in advanced cancer. Support Care Cancer 2007;15:1051-1056.

44. Brooks J, Wilson K, Amir Z. Additional financial costs borne by cancer patients: a narrative review. Eur J Oncol Nurs 2011;15:302-310.

45. Bradley CJ, Neumark D, Luo Z, Schenk M. Employment and cancer: findings from a longitudinal study of breast and prostate cancer survivors. Cancer Invest 2007;25:47-54.

46. Timmons A, Gooberman-Hill R, Sharp L. The multidimensional nature of the financial and economic burden of a cancer diagnosis on patients and their families: qualitative findings from a country with a mixed public-private healthcare system. Support Care Cancer 2013;21: 107-117.

47. Zafar SY, Peppercorn JM, Schrag D, Taylor DH, Goetzinger AM, Zhong X, et al. The financial toxicity of cancer treatment: a pilot study assessing out-of-pocket expenses and the insured cancer patient's experience. Oncologist 2013;18:381-390.

48. Zafar SY. Financial toxicity of cancer care: It's time to intervene. J Natl Cancer Inst 2015;108:djv370.

49. Yang D, Kim H, Kang E, Kim D, Bae E, Kim J. Patterns and determinants of catastrophic health expenditure in the households with cancer patients. Korean J Health Econ Policy 2017;23:53-70.

50. Chin YR, Lee IS, Lee HY. Effects of hypertension, diabetes, and/or cardiovascular disease on health-related quality of life in elderly Korean individuals: a population-based cross-sectional survey. Asian Nurs Res 2014;8:267-273.

51. Bardage C, Isacson DG. Hypertension and health-related quality of life: an epidemiological study in Sweden. J Clin Epidemiol 2001;54: 172-181.

52. Naeim A, Dy SM, Lorenz KA, Sanati H, Walling A, Asch SM. Evidencebased recommendations for cancer nausea and vomiting. J Clin Oncol 2008;26:3903-3910.

53. Ravasco P, Monteiro-Grillo I, Vidal PM, Camilo ME. Cancer: disease and nutrition are key determinants of patients' quality of life. Support Care Cancer 2004;12:246-252.

54. Ravasco P, Monteiro-Grillo I, Camilo ME. Does nutrition influence quality of life in cancer patients undergoing radiotherapy? Radiother Oncol 2003;67:213-220.

55. Mantovani G, Macciò A, Massa E, Madeddu C. Managing cancer-related anorexia/cachexia. Drugs 2001;61:499-514. 